\title{
11 Addressing climate policy-making and gender in transport plans and strategies
}

\author{
The case of Oslo, Norway
}

\author{
Tanu Priya Uteng, Marianne Knapskog, André \\ Uteng, and Jomar Sæterøy Maridal
}

\section{Introduction}

Land use and travel behaviour remain closely conjunct and, since the 1990s, European nations have developed planning guidelines for integrated land use and transport development. These planning guidelines have also addressed overarching themes like universal design, improving conditions for children and youth and a more sustainable society. Lately, efforts have been directed towards examining the overlaps between sustainable planning and the climate policy-making agenda, but fine-grained analyses are largely lacking. To this end, gendered travel behaviour and its impacts on climate goals present a glaring research gap.

We begin with analysing the Norwegian planning and climate policy agenda by focusing on the case of Oslo. The scope of investigation is limited to presenting a quantifiable base for analysing gendered travel behaviour, both the existing patterns and in light of upcoming solutions like electrification and shared mobility, which are being posited as sustainable solutions. The topic is analysed under two thematic domains - administrative and demographic - which are sewed together in the end.

Through analysis of planning documents and information available to the public and private sector planners, the intention is to uncover the presence of (climate) strategies in plans, tools and other essential factors on the national, regional and local scale and then to analyse the results in light of gendered patterns of daily mobilities.

Three types of plans are especially important to climate policy-making land use plans, climate action plans and mobility plans. These three different types of plans address crucial aspects of climate policies. In Norway, strategies for modifying travel behaviour saturate the plans and form a core component of strategic land use and mobility plans. Electrification comes across as part of the solutions to abate emissions and become fossil-free. At the European level, other types of sustainable fuels like hydrogen and biogas are more prominent, but Norway has concentrated on electrification. The voluminous growth of electric cars in Oslo is often used as a benchmark for electrification of vehicles across the world. 
Distribution impact and acceptability of land use and transport solutions are not explicit in the planning documents. On the surface, the plans treat the entire population as a homogenous unit. The most important organising principle in the plans is the national zero-growth objective $(\mathrm{ZGO})^{1}$ for private car use, prioritising those who drive less and use more sustainable modes of transport. Gendered and segregated analyses, however, do not form part of the current approach and discussions. There is much to gain from disaggregated analyses. For example, travel patterns for the city of Malmö in Sweden highlighted that if women were to adopt the travel patterns of men, the modal share by car would increase by $17 \%$ and $\mathrm{CO}_{2}$ emissions from car traffic would increase by $31 \%$. Further, an additional demand for driving and parking space would add up to 190 standard town squares (Svanfelt, 2018). Building on these arguments, this chapter explores the nexus between gendered travel behaviour and climate policy-making by concentrating on the following question: How can transport and climate policy-making be better understood and conceptualised in light of gendered travel behaviour?

The chapter is structured as follows: the second section briefly introduces gendered travel behaviour and the third, the theoretical framing informing this study. The fourth section outlines the method, while the contextual background of the case city Oslo is presented in the fifth section. A brief content analysis of the major policy documents guiding Oslo's climate policy-making in the field of urban-transport planning is outlined in the sixth section, and a quantitative assessment of current and future travel behaviour, based on a macro-based prognosis-model called DEMOTRIPS, is summarised in the seventh section. The final section presents the concluding discussion and argues for more nuanced, disaggregated analyses to be made integral to climate policy-making exercises undertaken in future. The overall framing of the chapter is guided by an acknowledgement that current climate policy-making exercises will fail to deliver the desired results if policies and programmes do not recognize the contextual realities of current and future travel behaviour. Men and women show a consistent difference in their needs, preferences and practices of daily mobility which produces different bundles of climate effects at an aggregate level and, thus, differential marketing and targeting of future interventions are required to align travel behaviours with the goals of climate policies.

\section{Gendered patterns of daily mobilities}

In order to build a case for linking gendered travel behaviour and climate goals, this section presents the main findings emerging from a literature review of research and projects with direct impacts for climate policy-making. It is notable that there is a consistent pattern of women's daily mobility across the world with evident differences on a range of topics characterising the travel behaviour of women versus men (Priya Uteng and Creswell 2008).

Though car license-holding for women in the Global North has risen sharply in recent decades (Hjorthol, 2008), this development has not automatically led to an equal distribution of car-driving between men and women. Women are 
still, to a greater degree, car passengers than men (Polk, 2003). Women have a strong preference for sustainable modes of transport as they both use more public transport and have higher walking frequency compared to men. Given their propensity to use more public transport, to walk more and their high incidences of trip-chaining, women use multiple modes rather than a single mode (Heinen and Chatterjee, 2015). Women travel shorter distances, and their trip duration is also limited compared to men. This is evident in their commuting or work-related trip patterns but holds true for other trip purposes as well (Hjorthol, 2008; Sandow and Westin, 2010; Scheiner et al., 2011; Kim et al., 2012). In comparison to men, long-distance commuting remains much more restricted for women (Sandow, 2008; Scheiner et al., 2011; Hjorthol and Vågane, 2014).

Given the unabated development of car-based societies, it is not surprising that certain travel trends exhibit converging tendencies over time for the respective genders. As Konrad (2015) and Scheiner (2018) comment, elements of license-holding, car availability, mode choice (car driving), trip distances and trip duration seem to be converging over time. However, we need to analyse these converging tendencies in light of what Scheiner (2018) calls attention to - women are perhaps less habitual, more responsible, more sustainable and more sociable (Matthies et al., 2002; Polk, 2003; Hjorthol, 2008). This effectively means that the converging and shifting of women's sustainable travel behaviour towards a car-based, unsustainable one could be in response to the structural conditions that have underpinned city planning in the past decades. These trends also indicate that there has been a gradual evolution of an unsustainable path dependency (overlapping with the feminist institutional approach discussed in the introduction chapter) toward car-use in city planning which has pushed women to choose unsustainable transport mode. This shift has some serious implications, both from the perspectives of climate change (in line with the zerogrowth objective) and the inclusivity agenda which insists the cities should be designed to be more inclusive and cater to the needs of its various demographic groups - women, children, elderly, disabled, immigrants etc. However, research simultaneously indicates that this (unsustainable) shift can be steered towards a more sustainable direction through the creation of conditions conducive to walking, cycling, and public transport (Priya Uteng et al., 2020). The ongoing global discussions on creating 15-minutes post-COVID-19 cities also rest on the modus operandi of increasing accessibility by walking and cycling to core facilities like grocery, health and other basic amenities (C40 cities climate leadership group 2020).

\section{Gender and climate policy-making}

The literature review highlights that a substantial amount of discussion so far has veered towards the gendered nature of the politics and management of climate change agenda. Findings suggest that females have greater awareness and concern about climate change than males (McCright, 2010; McCright and Dunlap, 2011) and the differences in attitude are often attributed to qualities such as cooperation 
and care, frequently associated with women (Gilligan, 1982; Beutel and Marini, 1995). Mavisakalyan and Tarverdi (2019) note that there is a positive correlation between a country's female representation and the 'stringency of its climate change policies'. For example, in Denmark, with a female representation of $37 \%$, the stringency of climate change policies is eight times more than Bahrain with a female representation of $2 \%$. An attempt to quantify this relationship highlights that a ten-unit increase in female representation results in a decrease of 0.24 metric tonnes of carbon dioxide per capita (ibid). This correlation provides substantial support to the claim that increased female representation in national parliaments results in more stringent climate change policies, thereby resulting in lower carbon dioxide emissions and campaigns targeting climate policy change are more successful in nations with higher female representation.

Other findings from Scandinavia problematise a simple correlation between female representation and a more sustainable climate agenda (Magnusdottir and Kronsell, 2014; Winslott Hiselius et al., 2019). Kronsell (2013, p. 12) issues an advisory remark:

Gender sensitivity will not come about simply through the inclusion of women in policy-making. The practice of regimes, and the norms that constitute the social order of the landscape are all important to climate governance, and hence, they too, have to be actively scrutinised for gender and other injustices.

Kronsell (2013) argues for the adoption of the following three processes to bolster this interlocking: to strengthen female participation, to deal with oppressive power relations, and to challenge institutionalised norms. The core message is that there is a categorical lack of knowledge on how to deal with the topic of 'gender', and following Kronsell's claims (2013), for equal representation to have a substantial effect, we need actors who are knowledgeable on gender relevance of climate issues and who are interested in change and transformation, but were previously excluded from climate governance.

A second strand of focus in research builds on gender mainstreaming, which ECOSOC (1997) describes as following:

The process of assessing the implications for women and men of any planned action, including legislation, policies or programmes, in all areas and at all levels. It is a strategy for making gender an integral dimension of the design, implementation, monitoring, and evaluation of policies and programmes in all political, economic, and societal spheres so that women and men benefit equally, and inequality is not perpetuated. The ultimate goal is gender equality.

Alston (2014) argues that while gender mainstreaming has been widely accepted, there exists a lack of understanding of its goals. This argument resonates with the transport field as well. Bacchi and Eveline's (2010) claim, that there is a lack of understanding of the actual problem and therefore the need to perform a rigid 
gender analysis of policies and outcomes and identify the actual problem being solved, hits the bullseye for the problem at hand in the transport domain. For example, the framing and understanding of the actual problem - how to decrease car use and thus address the zero-growth objective in Norwegian urban areas - is currently not being sieved through a gendered lens and consequently gender analyses do not inform the current climate policy-making exercises in Oslo.

Thus, though the first argument about the politics and management of climate policy-making in light of gendered positioning remains important, it needs further bolstering. This argument is repeated in the gender-mainstreaming agenda as well. Alston (2014) argues that whilst gender mainstreaming strategies include providing gender-disaggregated data, gender auditing, gender budgeting and greater transparency on factors such as the number of women in leadership positions, this is not enough to promote substantial change. Gender-mainstreaming goals often conflict with conservative bureaucratic processes and norms in terms of path dependencies (Chapter 1, this volume) which reduces the ability to make substantial changes (Wittman, 2010). Alston (2014) stresses the need to review and reassess policies and actions to ensure that they do not reinforce or create new gender inequalities.

A third line of enquiry is rooted in the gender role congruity theory which proposes that men and women engage in behaviours that are congruent with traditional gender roles (Eagly, 1987; Eagly et al., 2000). Swim et al. (2018) propose that climate policy arguments that focus on science and business are associated with men, whilst climate policy arguments that focus on ethical and environmental justice systems are associated with women.

Relying on any one particular strand might render the arguments unbalanced and, thus, it becomes important to attend to the question of how to bring these strands together. The field of transport provides a unique opportunity to sew together the science-business and ethics-justice frames when discussing climate change policies (Sovacool et al., 2018). Analyses presented in this chapter confirm that, both in current times and in the future, women exhibit sustainable travel behaviour and a higher usage of walking, cycling and public transport, while being less dependent on cars compared to men. These findings demonstrate that rather than being mere proponents of the ethics-justice frame being applied to discussions on climate change, women's travel behaviour makes them active agents of the science and business of designing transport policies. And it is utmost essential that these findings are taken forward in the practices and the norms guiding the designing of transport policies to cater to climate goals.

\section{Methods}

The chapter combines the qualitative method of content analysis with a quantitative prognosis model. In order to provide an overview of the connections between gendered travel behaviour and climate policy-making strategies, we employed content analysis of planning documents. The intention was to highlight the climate strategies in plans, tools and other essential factors on the national, 
regional and local scale, and check if and how the gender component is being taken forward. Though the primary focus was on strategic planning documents of the municipalities, due attention has also been paid to the regional and national plans as they are an integral part of the framework for climate policies. The content analysis investigated the plans and not the planning processes or political discussions per se. Plans and strategies are crucial as the starting point for further discussions and are, therefore, an essential part of the framing, formulating and providing a vocabulary for possible solutions in designing climate policies.

The second method focuses on a macro-based prognosis-model called DEMOTRIPS, a model used to assess the travel trends and demographic changes of men and women in the city of Oslo. The model uses current travel data, elasticities reflecting the relationship between transport modes, logistical growth modelling and the expected demographic development within specified geographical areas to create a prognosis for future travel behaviour. Additionally, DEMOTRIPS extends the analysis beyond women and men to include the intersectional category of age.

\section{The case of Oslo}

Oslo, Norway's capital, is the largest city and urban region of the country. The current platform for city council, cooperation between the Labour Party, the Green Party and the Socialist Left Party in Oslo (2019-2023), has employment for everyone, abatement of climate change and social equity as the most critical priorities. An important goal is to become the world's first emission-free city by 2030. The red-green coalition aims to govern the city according to a climate budget to reach $95 \%$ cut in greenhouse gas emissions by 2030 , along with reducing Oslo's contribution to greenhouse gas emissions outside the municipality and an approximately one-third reduction in Oslo's car traffic by 2030 compared to the 2015 level. The city council aims to make explicit climate change effects and consequences in all relevant plans that are submitted to the city government.

Oslo is both a county and a municipality. The municipality is responsible for implementing the national, regional and local policies and translating them into local solutions along with attending to budgetary details. Most of the strategic planning takes place at the municipal level. In the first half of the four-year local election period, each council adopts a political strategy for municipal planning and decides ways to revise the municipal master plan. The adopted municipal master plan comprises the framework for preparing local plans and processing cases and is legally binding.

Further, though the regional plans could have been legally binding after the Planning and Building Act was modified in 2008, the county chose not to make the regional plan legally binding. So, in the case of Oslo, the regional plan remains advisory and provides the foundation for the municipality plans guiding the ZGO. For transport-related tasks that cover larger areas or overlap between municipal levels, there are two relevant items to be discussed - Ruter and the urban growth agreement for Oslo and Akershus. 
Ruter is the public transport agency in charge of the administration of the tram, metro and buses in Oslo. Oslo and parts of the neighbouring county of Viken own Ruter. As a rule, Ruter oversees both tendering of public transport services and drafting the public transport strategy. In 2019, the national government, the county of Akershus (now part of Viken), the transport agencies, the municipality of Oslo as well as neighbouring municipalities of Skedsmo, Bærum and Ullensaker agreed to sign an urban growth agreement. The aim is to reach $\mathrm{ZGO}$ by implementing the regional plan and extending one part of the public transport network.

Table 11.1 shows the relationship between the main plans for climate policy-making on different levels that are valid for Oslo. As a rule, the laws, rules and guidelines come from the national government. At the regional level, the regional plan for land use and transport and the public transport plan is valid both for the city of Oslo and the Akershus region. The municipality oversees the land use, thematic (action) plans, and climate budget.

\section{Content analysis of policy documents}

This section presents the results of the content analysis of the policy documents outlined in Table 11.1.

\section{Regional plan for land use and transport}

The regional plan for land use and transport in Oslo and Akershus was approved in 2015 by both the Municipality of Oslo and the neighbouring county of Akershus (now part of Viken) (Plansamarbeidet, 2015). The plan, a joint strategic platform outlining the strategies to achieve efficient coordination between land use and transport in the region, is not legally binding but provides the foundation for further strategic planning in Oslo and the municipalities of Akershus County. The plan, gaining further momentum by an urban growth agreement that is accepted at all government levels, covers the following issues: densification,

Table 11.1 Strategic climate policy framework for Oslo 2020

\begin{tabular}{|c|c|c|}
\hline Government level & Area & Plans and policies \\
\hline $\begin{array}{l}\text { State/national } \\
\text { level }\end{array}$ & National & $\begin{array}{l}\text { Laws including rules and regulations, National } \\
\text { transport plan, thematic initiatives, zero- } \\
\text { growth goal (private car use), urban growth } \\
\text { agreements }\end{array}$ \\
\hline $\begin{array}{l}\text { County/regional } \\
\text { level }\end{array}$ & $\begin{array}{l}\text { Oslo and Viken } \\
\text { (and the wider } \\
\text { Oslo region) }\end{array}$ & $\begin{array}{l}\text { Regional plan for integrated land use and } \\
\text { transport, public transport plans (Ruter), } \\
\text { Policy package for transport (Oslopakke } 3 \text { ) }\end{array}$ \\
\hline Municipality & Oslo & $\begin{array}{l}\text { Municipal master plan, climate budget, thematic } \\
\text { plans and strategies including climate budget, } \\
\text { climate action plan, bicycle plan }\end{array}$ \\
\hline
\end{tabular}


multicore development and zero-growth in transport demand, supported through better accessibility for walking, cycling and public transport.

The ZGO is the overarching goal implying that private car travel demand should be gradually diminished, in addition to halving greenhouse gas emissions by 2030. The plan seeks to modify travel behaviour through denser land use, prioritising some urban centres or nodes and local communities for development over others, leading to better integration between land use and public transport. The plan envisages increasing public transport supply as a vital measure to lower emissions. Cycling and walking are also posited as necessary tools to get a sustainable transport system and emphasis is put on improving the system, maintenance of the bicycle infrastructure and snow clearing in winter. Besides, the plan instructs municipalities to introduce more restrictive parking regulation that is adapted to the local context.

In summary, the regional plan has a focus on local accessibility in some nodes and towns aiming at access to services, jobs, housing and public transport within walking distance as an organising principle. However, it is not discussed how different demographic groups will be affected by the proposed plan. Further, there is no mention of gendered analyses or upcoming shared modes of travel.

\section{The municipal master plan of Oslo}

Oslo City Council approved the municipal master plan for Oslo in 2015 along with the regional plan. The master plan for Oslo is divided into social and land use elements where the latter is legally binding and consists of thematic maps, regulations and guidelines. The social element of the municipal master plan was revised in 2018 and renewed the urban strategy to guide revisions of the land use plan (Municipality of Oslo, 2015 and 2019). The plan, finalised by the Oslo City Council in 2019 and valid until 2040 (Municipality of Oslo, 2019), covers the following main issues: changing the pace of adoption of climate and environmental policies, active and sustainable municipality and equity (or social sustainability).

The plan aims at making Oslo a zero-emission city by 2030, and the strategies include building the city from the inside out and locating businesses in climatefriendly locations with good public transport access. According to the plan, the city has a significant potential to reduce pollution if the vehicle fleet becomes emissionfree and there is a modal shift from cars to public transport, cycling and walking.

The plan seeks to modify travel behaviour by making car travel more difficult and at the same time making travel by public transport more accessible and improving the urban structure around the public transport nodes. Neighbourhoods are to become self-sufficient so that the need for daily travel (apart from commuting to work) will be reduced or based on sustainable forms of transport. Additionally, the plan talks about the electrification of the car fleet. The municipality will change its car fleet to electricity, hydrogen, or biogas and facilitate private (primarily electric) car use by supplying charging stations. The electric car facilitation is also a part of Oslo's Smart City project. Further, the 
plan integrates shared mobility (car sharing, bike sharing) and new modalities (for example, MaaS - mobility-as-a-service) in its outlook to mobility.

In summary, the municipal plan repeats the focus on local accessibility and embraces electrification and upcoming smart mobility solutions. But even though this plan makes explicit mention of equity and social sustainability, it does not delve into how different demographic groups and their travel behaviour will be affected by the proposed plan. There is no mention of gendered analyses even though the focus is at the municipal level and detail, disaggregate, gender data is readily available.

\section{Climate and energy strategy and climate budget}

Another important plan for Oslo is the climate and energy strategy (valid from 2016 to 2020) (Municipality of Oslo, 2016). The main themes deal with reducing car traffic, densification along the railway network and public transport hubs, increased bicycle share and reduced vehicle kilometres. The climate management part aims at integrating climate budgets into the municipal budget processes, practising environmentally efficient procurement, working closely with citizens and assisting organisations and other public authorities to develop and implement the right climate solutions.

Implementation is undertaken through the climate budget. In addition to the normal budget focusing on the municipal economy, Oslo has a climate budget highlighting the importance of sustainable development. The climate budget of 2019 was the third budget for Oslo and was essentially a list of measures the city council plans to implement for one year. The plans calculate the impact of emissions for each measure. The overall aim of the climate budget is twofold. Firstly, the climate budget highlights if the set targets will lead to an estimated reduction in emissions. Secondly, the budget stipulates the different municipal units responsible for reporting the results during and after the implementation.

In summary, the principles of gender budgeting are yet to intersect with Oslo's climate budgeting processes. It is a relatively simple exercise to include a gendered analysis of the proposed measures and ways to prioritise and tackle the outcomes if a certain measure favours one demographic group over another. But such calculations haven't been undertaken in Oslo's climate budgeting exercises. For example, Oslo has spent a substantial amount of public money in creating dedicated bike lanes but initial analyses reveal that the relative location of these dedicated bike lanes might be favouring men who undertake high-speed cycling over women who don't (de Jong et al., 2018).

\section{Public transport strategy}

The public transport strategy, conceived by Akershus County and Oslo Municipality in 2016 and valid until 2020 (Ruter, 2016), is also rooted in the regional plan with a focus on densification. The strategy suggests combining mass transport with individual solutions. Ruter has calculated how the areas covered in the regional plan can reach the ZGO (see Table 11.2). Recent technological 
Table 11.2 The public transport company Ruter's estimate of reaching the zero-growth goal by 2030

\begin{tabular}{|c|c|c|c|c|c|c|c|c|c|c|}
\hline \multirow{8}{*}{$\begin{array}{l}\text { New trips } \\
\text { Growth } \\
\text { Market shares } \\
\text { Public transport } \\
\text { Bicycle } \\
\text { Walking } \\
\text { Sum }\end{array}$} & \multicolumn{2}{|c|}{ Inner-city } & \multicolumn{2}{|c|}{ Outer-city } & \multicolumn{2}{|c|}{$\begin{array}{l}\text { Regional cities } \\
\text { and central } \\
\text { areas }\end{array}$} & \multicolumn{2}{|c|}{$\begin{array}{l}\text { Sprawling } \\
\text { areas }\end{array}$} & \multicolumn{2}{|l|}{ Total } \\
\hline & $63 \mathrm{~m}$ & & $91 \mathrm{mi}$ & & $88 \mathrm{mi}$ & & $44 \mathrm{mi}$ & & 286 & \\
\hline & $25 \%$ & & $21 \%$ & & $19 \%$ & & $26 \%$ & & $22 \%$ & \\
\hline & 2014 & 2030 & 2014 & 2030 & 2014 & 2030 & 2014 & 2030 & 2014 & 2030 \\
\hline & $33 \%$ & $37 \%$ & $27 \%$ & $35 \%$ & $19 \%$ & $26 \%$ & $10 \%$ & $10 \%$ & $23 \%$ & $29 \%$ \\
\hline & $8 \%$ & $11 \%$ & $5 \%$ & $7 \%$ & $4 \%$ & $5 \%$ & $4 \%$ & $4 \%$ & $5 \%$ & $6 \%$ \\
\hline & $41 \%$ & $42 \%$ & $23 \%$ & $24 \%$ & $18 \%$ & $19 \%$ & $17 \%$ & $17 \%$ & $24 \%$ & $25 \%$ \\
\hline & $82 \%$ & $90 \%$ & $55 \%$ & $66 \%$ & $41 \%$ & $50 \%$ & $31 \%$ & $31 \%$ & $52 \%$ & $60 \%$ \\
\hline Car & $18 \%$ & $10 \%$ & $45 \%$ & $34 \%$ & $59 \%$ & $50 \%$ & $69 \%$ & $69 \%$ & $48 \%$ & $40 \%$ \\
\hline
\end{tabular}

Source: Ruter (2016)

innovations have led to new shared solutions that Ruter plans to integrate with traditional public transport. The plan shows that car traffic has stagnated while the bicycle and walking share remains unchanged in Oslo. Ruter believes that the substantial growth in public transport needs to be sustained through further investments in infrastructure, capacity enhancement and better connection with both existing and upcoming shared modes of transport.

\section{Bicycle strategy}

Oslo does not have a sustainable urban mobility plan or a walking strategy at present but is in the process of making a walking strategy. However, Oslo has a bicycle strategy (Municipality of Oslo, 2014) that was adopted by Oslo City Council in 2014 and is valid for ten years. It aims to increase the bicycle share to at least $16 \%$, which effectively means tripling the current bicycle share. The plan provides the foundation for a systematic working method to continuously improve conditions for cyclists in Oslo. Controlling emissions is a part of the overall strategy, and it is calculated that a bicycle trip that is five kilometres long emits 105 grams of $\mathrm{CO}_{2}$ (lifecycle analysis for the bicycle and bicyclist's calorie needs) while the same emission for a private car trip is 1,355 grams. The plan addresses shared mobility as well, and the municipality continues to play an active role in the city's bikesharing scheme. It is the only plan or strategy which recognises gendered behaviour, and highlights that men travel more with bicycles than women. And though the plan further acknowledges that increasing cycling shares will require different approaches for men and women, it is not able to engage with the topic in greater detail than a simple acknowledgement (Municipality of Oslo, 2014).

\section{Summing up}

A consistent finding throughout these different hierarchies of plans, guiding future transport solutions, is a lack of disaggregated analyses. Although the plans 
make perfunctory mentions of different areas and contexts, they do not engage with the gendered nature of travel behaviour. The framing of solutions relies heavily relies on a shift in travel behaviour without understanding these behaviours. Secondly, the technological domains of electrification, shared mobility, digitalisation and mobility-as-a-service (MaaS) are gaining traction in realising the overarching ZGO, and the domain of social sustainability in realising ZGO is lagging behind.

The point of contention is that none of the plans and strategies guiding future transport growth in Oslo undertakes a gendered approach to support the ongoing initiatives directed at increased usage of sustainable modes. The only plan or strategy that acknowledges gender at all is the bicycle strategy. Outside Oslo, the gender perspective is found in the walking strategy (that is still under construction in Oslo) in the small Norwegian town of Haugesund (Municipality of Haugesund, 2014). The walking strategy in Haugesund addresses disaggregated travel patterns, and the issue of safety, suggesting a more gendered walkability planning. But overall, the gendered perspective is almost non-existent in the current plans. Gendered analyses should be made an integral part of the planning strategies and planning documents ranging from the regional to the local levels. Not only will it ensure public support, but also give a grounded basis for infrastructure planning and provision.

\section{DEMOTRIPS analyses}

In light of the above conclusion, this section presents gendered analyses of Oslo's current and projected travel behaviour by employing the DEMOTRIPS model. DEMOTRIPS utilises the current travel data, elasticities between transport modes, logistical growth modelling and the expected demographic growth to create a prognosis for future travel behaviour. Through combining different elements, the model estimates how trends in mode usage within specified age groups and gender affect the usage of competing modes and the overall mode distribution in the area (model details available in Saeteroy Maridal 2018).

In order to discuss the gendered implications of current and future travel behaviour, we present two distinct travel scenarios for Oslo - the first is the business-as-usual (BAU) scenario which is built on the assumption that each age group and gender carries forward its present travel behaviour and is not affected by policies and programmes directed at ZGO; the second, or the zero-growth, scenario is built on the perception that car usage will reduce significantly but will be disproportionately divided among the different demographic groups given their ability to adopt other modes. The analyses are based on the following datasets:

- Population projections (extracted from Statistics Norway)

- Distribution of daily trips on different transport modes split by gender and trip length (extracted from The National Travel Survey [NTS] 2013/14) (Hjorthol et al., 2014)

- Mode substitution factors split by trip length 


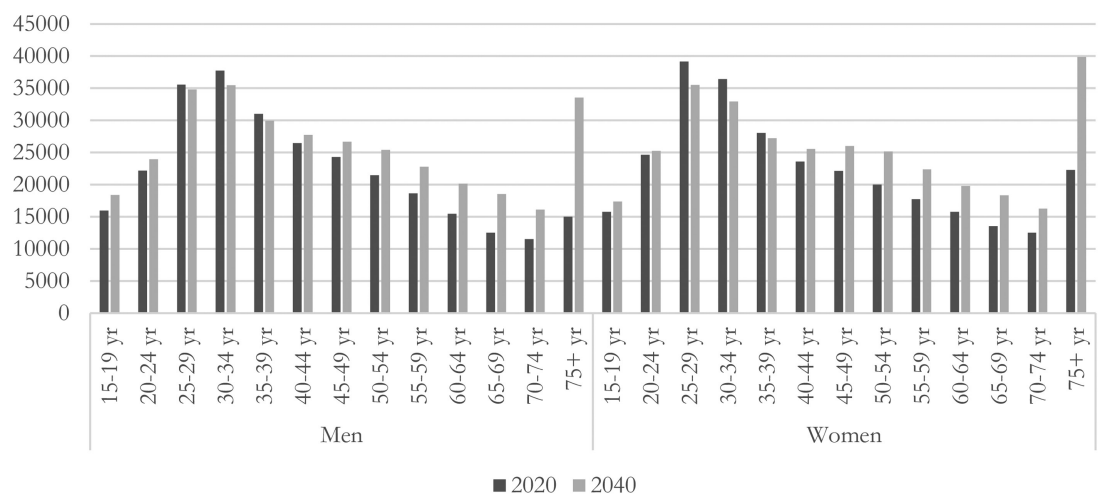

Figure 11.1 Oslo population by gender and age groups, 2020 versus 2040

Both scenarios contain short, medium and long trips, disaggregated by gender and age, as analyses based on travel behaviour surveys have consistently revealed that transport mode usage is highly dependent on the interaction between gender, age and trip length. Similar graphical representations and analyses are presented for the long, medium and short trips, providing a level of convenience to read and compare the results. Population projections indicate that by 2040, the disparity between youth and elders is larger in women than in men, although both genders are projected to have a spike in their elderly population. Women are also projected to see a stronger growth of established workers (40-64 age group) than men. These disparities feed into the scenario results and amplify the deviations in the existing gendered mobility patterns.

\section{Scenario Set A: Business as usual scenario (BAU)}

We present the BAU projections for short, medium and long trips disaggregated by gender and age. The first scenario explains and lays out the context of the data in detail to avoid being repetitive.

\section{Long trips}

Figure 11.2 illustrates an excerpt of the mobility data, denoting the mean number of daily long trips $(>7.5 \mathrm{~km})$ each age group currently undertakes on different modes of transport. What immediately stands out is that men are much more car-dependent than women on long trips. The disparity in the number of long-distance car trips, both in 2020 and 2040, is significant between the genders while the reverse relationship for public transport is not as strong, meaning that men travel at a higher rate on long daily trips than women. The implications of this, in a BAU framework, is that men's travel habits and population projections will influence overall mobility on long trips to a greater extent than women. In 


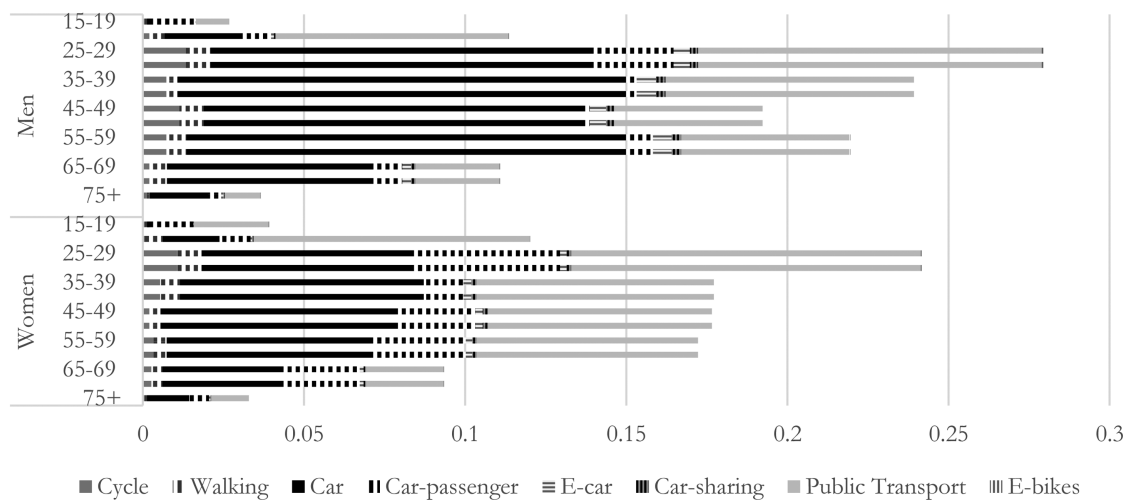

Figure 11.2 Oslo mean number of daily long trips per capita, BAU scenario

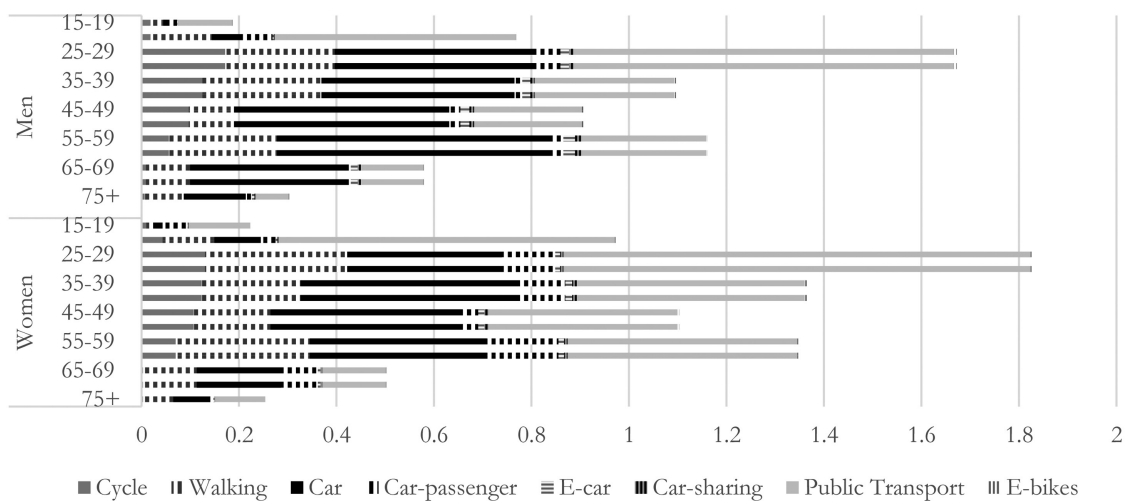

Figure 11.3 Oslo mean number of daily medium trips per capita, BAU scenario

terms of car travel, this is negative for the zero-growth objective because men are more car-dependent than women according to the current modal distribution. However, as the population's median age shifts towards the older demographics, overall mobility falls on account of a reduction in the mean number of trips. Still, car traffic growth is higher than public transport towards 2040.

\section{Medium trips}

Deviations between the genders are present in medium trips $(2.5-7.5 \mathrm{~km})$ as well (Figure 11.3). Women have a much higher public transport modal share than men and the difference in car dependence between men and women is also furthered by women being car passengers at a much higher rate than men. It becomes clear that though men and women have more similar car mobilities 


\section{Priya Uteng, Knapskog, Uteng and Sæterøy Maridal}

in medium trips than in short trips in terms of distribution across age groups, women lack the car-use spike between the ages of 25 and 34 as seen in men. This is, however, present in public transport, where women have considerably more trips at the aggregate level than men, illustrating that in the medium trip length as well, men are much more car-dependent than women. However, the fact that the number of car trips is relatively high in the older age groups as well as amongst 25-34-year-olds, for both genders, is challenging with respect to the zero-growth objective. An even distribution of car ridership combined with the skewed distribution of sustainable mode ridership towards younger age groups may translate into an increased car dependence in the years to come due to the population's rising median age.

\section{Short trips}

Deviations between men and women's mobility patterns exist for short trips $(<2.5$ $\mathrm{km})$ as well (Figure 11.4). It is evident that for short-distance trips, men are driving considerably more than women. The distribution in walking trips, on the other hand, is surprisingly similar between the two genders although the overall walking mobility is also higher amongst men than women. The only deviation that stands out is that women over 75 years of age walk considerably more than men.

\section{Summary}

With respect to the zero-growth objective, mobility patterns of both men and women will result in a strong relative increase in car ridership vis-à-vis other modes, but in different ways: women have a broader age group spike in car ridership than men, which means that even though the population's median age is projected to move upwards, it will still fall within one of the age groups where car ridership is high. For men, the ridership spike is narrower (consigned to 35-44-year-olds) but

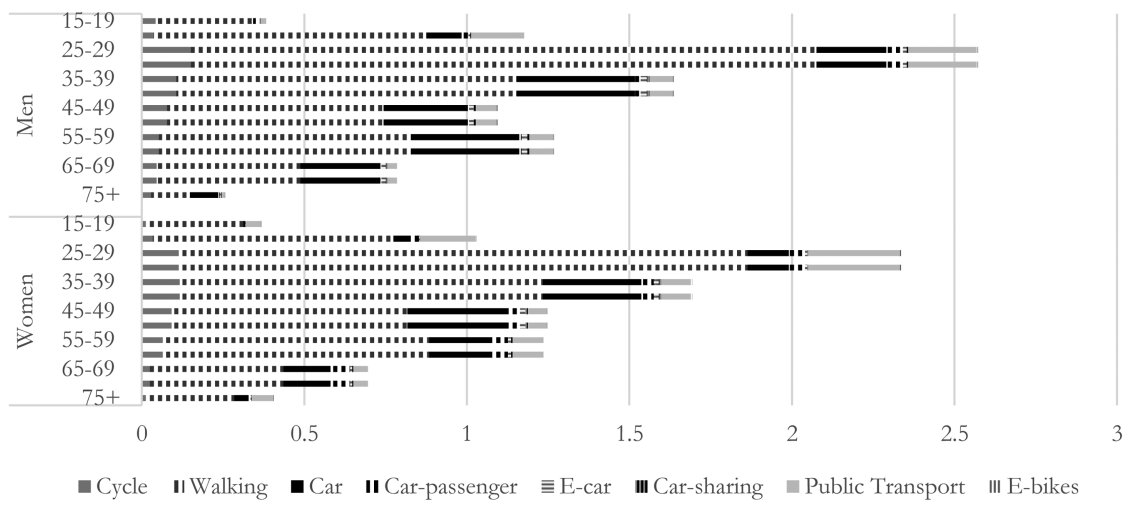

Figure 11.4 Oslo mean number of daily short trips per capita, BAU scenario 
the elder demographics in men that today constitute a smaller share of the overall population are even more car-dependent than 35-44-year-olds, according to current mobility distributions. The influx of men aged over 45 will, thus, increase the overall car share for men relative to other modes.

According to the BAU trajectories presented, total car travel is expected to rise by $11 \%$ from 2020 to 2040 which means that 39,824 daily long, medium and short car trips need to be substituted by either walking, cycling, or public transport by 2040 if the zero-growth objective is to be met.

There are, however, both positive and negative aspects of the BAU scenarios with respect to the zero-growth objective. On a positive note, overall mobility per capita is projected to fall which means that at the aggregate level, slightly fewer daily trips will be undertaken in 2040 than in 2020. This is derived from population projections where the median age is expected to rise. Across the three scenarios, 25-34-year-olds conduct the highest number of daily trips and an ageing population means that these demographics will soon constitute a smaller share of the overall population, resulting in lower rates of mobility. This is, of course, assuming that the age groups' rates of mobility remain constant towards 2040. As for negative implications, the projected car traffic growth is disproportionally high relative to the projected growth in sustainable modes of transport across the three categories of trip lengths. This is because cars, in general, make up a larger share of overall mobility amongst the elder age groups (cf. men). A rising median population age combined with a general population influx thus translates into elders' travel habits increasingly affecting overall mobility, making Oslo's future mobility more car-oriented.

\section{Scenario Set B: Achieving a zero-growth objective (ZGO)}

In presenting the zero-growth scenarios, we plotted the trajectories where the sustainable modes identified by the Nation Transport Plan (NTP) have been set to grow and where mode substitution factors have been introduced to the model framework. The goal is to analyse how a zero-growth development in car traffic could unfold with an emphasis on the gendered responses to the growth rates and constraints set in terms of their projected mobility outputs.

\section{Long trips}

The main 'problem' for the elder groups in general and those above 75 years of age, in particular, is not that the trips are not transferred away from cars, but rather that the population increase is so massive in this demographic group that the overall number of trips conducted for all modes will grow despite the transfers to more sustainable modes. Analyses clearly demonstrate that public transport is absorbing prospective car trips for all demographics. The differing rates of car ridership transfers between the age groups are due to two factors: population increase and its associated rising median age, and the mode substitution factors' effect on altering mobility habits. Deviations indicate that there is a lower level 
of probability for elders to shift onto public transport in long trips than what is the case for the younger age groups. The implication of this is that the habitual change needed to substitute public transport for car travel becomes even higher with increasing age.

\section{Medium trips}

On medium trips, there is a decreasing rate of relative transfers from car travel in older age. The total number of car trips is up for men over 75 years of age in 2040 compared to 2020. Women also demonstrate the same tendency, but the overall number of car trips still falls across all age groups for women. The same mechanisms are at play here as in long trips - the projected population growth, skewed towards the older age groups, results in these demographics having more trips than before. Note that amongst 25-34-year-olds, the relative decline in car trips is much stronger for women than for men. The same transfers happen to a lesser extent for men, while women in this age group are seemingly easier to shift from cars to the other sustainable transport modes in this scenario. Women, in almost all age groups, will have gone from being relatively car-dependent to relying on public transport, cycling and walking for their trips by 2040, but the same cannot be said for men. Middle-aged and older men are projected to remain car-dependent on account of their mode substitution factors, ${ }^{2}$ which explains the lower rate of transfers from cars to other modes like public transport, bicycling and walking.

\section{Short trips}

The decreasing rate of negative transfers from cars to sustainable modes is also present for short trips, but only for men. Here, 75+-year-olds end up having slightly more car trips in total in 2040 than in 2020, partially due to this age groups' relatively high population growth. This development is, however, not present in the same way amongst women, where car ridership falls considerably for all age groups. Both in men and women, the relative fall in car ridership is the strongest amongst 20-29-year-olds who seem to be particularly ready to substitute cars for sustainable modes in short trips, and 40-44-year-old women also demonstrate this tendency. It is worth noting that women, in general, conduct much fewer daily short-distance car trips than men. The total number of cycling trips is also projected to fall for 25-39-year-olds. The driving factor behind this projection is not that these age groups do not transfer car trips onto cycling trips, but because the overall population within these groups is projected to decline. There are also strong rates of substitution between walking and cycling on short trips.

\section{Summary}

The zero-growth scenarios found a clear indication that growth rates for sustainable modes need to be stronger for older age groups than for the younger ones to 
Table 11.3 ZGO Scenario growth rates and aggregate mode shares, long trips

\begin{tabular}{lllllllll}
\hline & Cycling Walking Car & $\begin{array}{l}\text { Car- } \\
\text { passenger }\end{array}$ & $\begin{array}{c}\text { El-car Car- } \\
\text { sharing }\end{array}$ & $\begin{array}{l}\text { Public } \\
\text { transport }\end{array}$ & El-cycle \\
\hline $\begin{array}{c}\text { Yearly growth } \\
\text { rate }\end{array}$ & $4 \%$ & $3 \%$ & $0 \%$ & $0 \%$ & $0 \%$ & $0 \%$ & $7 \%$ & $4 \%$ \\
$\begin{array}{c}\text { Mode shares } \\
\quad 2020\end{array}$ & $3.5 \%$ & $2.9 \%$ & $39.1 \%$ & $9.5 \%$ & $1.2 \%$ & $0.9 \%$ & $42.8 \%$ & $0.1 \%$ \\
$\begin{array}{c}\text { Mode shares } \\
2040\end{array}$ & $3.5 \%$ & $2.8 \%$ & $22.0 \%$ & $7.5 \%$ & $1.2 \%$ & $0.9 \%$ & $61.8 \%$ & $0.1 \%$ \\
\hline
\end{tabular}

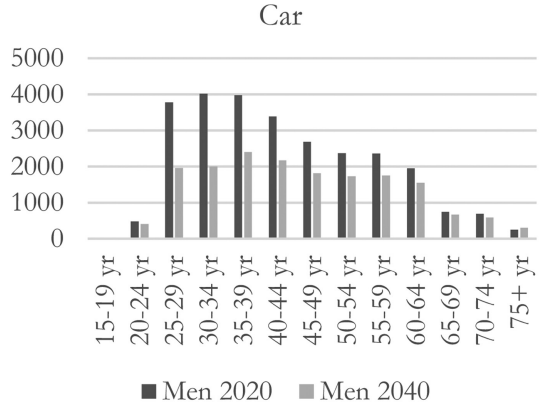

Public transport

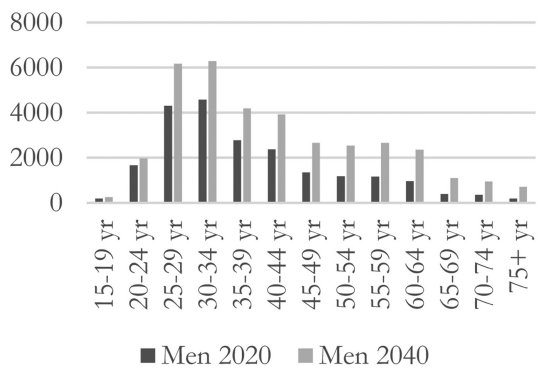

Car

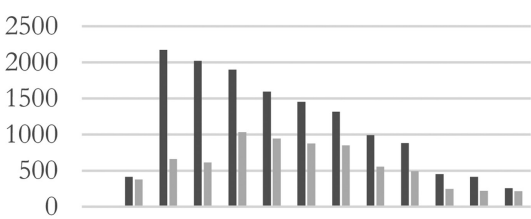

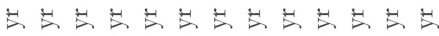

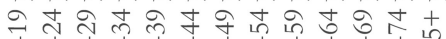

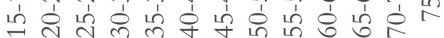

- Women 2020 - Women 2040

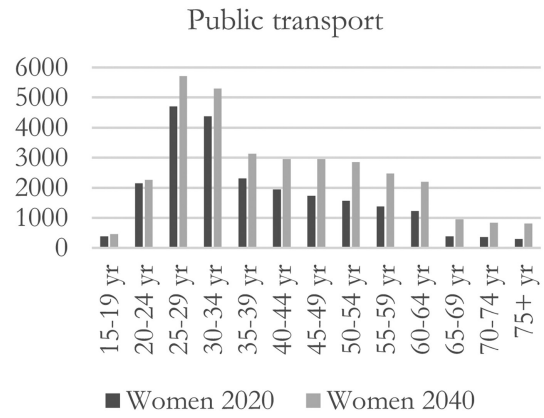

Figure 11.5 ZGO Scenario number of trips on select modes by age group and gender, long trips

achieve zero-growth in car traffic. This applies across all trip lengths. Three factors cause the above effect: older people, in general, being more car-dependent than younger people, the demographic shift in terms of an ageing population, and elders having weaker mode substitution factors from cars onto sustainable modes on some trip lengths. The population effect in particular will make it hard for elders to maintain overall car travel at today's levels. The age groups corresponding to established workers generally have a high car dependency per capita both now and in 2040. However, this demographic can still be projected 
Table 11.4 ZGO Scenario growth rates and aggregate mode shares, medium trips

\begin{tabular}{lllllllll}
\hline & Cycling Walking Car & $\begin{array}{l}\text { Car- } \\
\text { passenger }\end{array}$ & El-car & $\begin{array}{l}\text { Car- } \\
\text { sharing }\end{array}$ & $\begin{array}{c}\text { Public } \\
\text { transport }\end{array}$ & El-cycle \\
\hline $\begin{array}{c}\text { Yearly growth } \\
\text { rate }\end{array}$ & $7 \%$ & $4 \%$ & $0 \%$ & $0 \%$ & $0 \%$ & $0 \%$ & $6 \%$ & $7 \%$ \\
$\begin{array}{c}\text { Mode shares } \\
2020\end{array}$ & $8.3 \%$ & $16.3 \%$ & $25.6 \%$ & $4.6 \%$ & $0.7 \%$ & $0.6 \%$ & $43.5 \%$ & $0.3 \%$ \\
$\begin{array}{c}\text { Mode shares } \\
2040\end{array}$ & $9.7 \%$ & $17.7 \%$ & $12.6 \%$ & $3.0 \%$ & $0.7 \%$ & $0.6 \%$ & $55.3 \%$ & $0.4 \%$ \\
\hline
\end{tabular}

Car

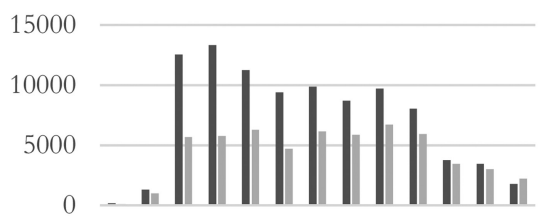

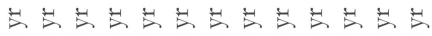

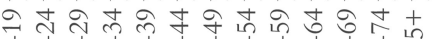

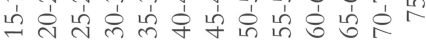

- Men 2020 men 2040

Public transport

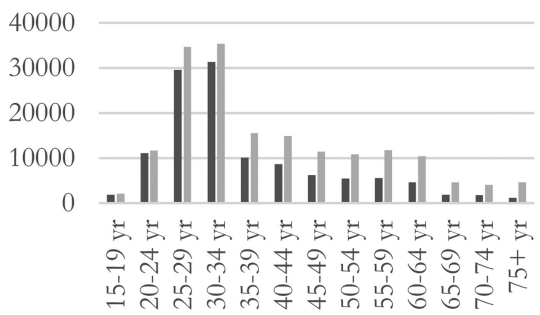

- Men 2020 Men 2040

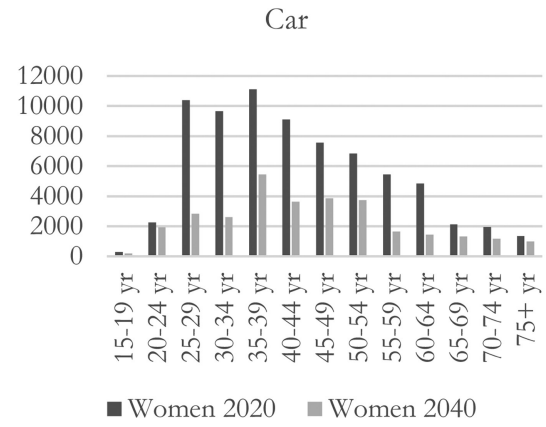

Public transport

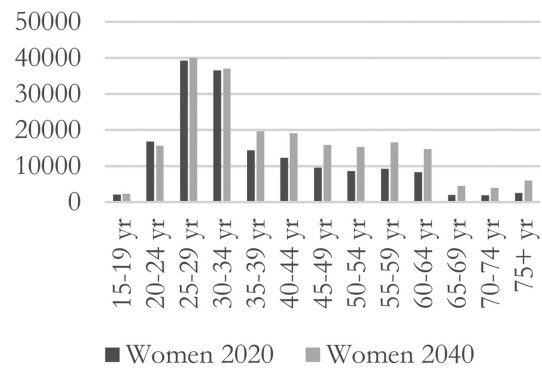

Figure 11.6 ZGO Scenario number of trips on select modes by age group and gender, medium trips

to achieve zero-growth in car traffic because its population growth is expected to be somewhat weaker than the oldest age groups. In general, men prove harder to shift away from cars and to sustainable modes than women, partly due to men being more car-dependent than women. This is particularly true for medium trips $(2.5-7.5 \mathrm{~km})$. 25-34-year olds, while having the highest rates of mobility of all age groups, are relatively easily transferred to sustainable modes on account of their mode substitution factors and low car dependence. Successfully shifting 
Table 11.5 ZGO Scenario growth rates and aggregate mode shares, short trips

\begin{tabular}{lllllllll}
\hline & Cycling Walking Car & $\begin{array}{l}\text { Car- } \\
\text { passenger }\end{array}$ & $\begin{array}{c}\text { El-car Car- } \\
\text { sharing }\end{array}$ & $\begin{array}{c}\text { Public } \\
\text { transport }\end{array}$ & El-cycle \\
\hline $\begin{array}{c}\text { Yearly growth } \\
\text { rate }\end{array}$ & $7 \%$ & $5 \%$ & $0 \%$ & $0 \%$ & $0 \%$ & $0 \%$ & $3 \%$ & $7 \%$ \\
$\begin{array}{c}\text { Mode shares } \\
2020\end{array}$ & $5.6 \%$ & $72.2 \%$ & $11.4 \%$ & $1.8 \%$ & $0.4 \%$ & $0.3 \%$ & $8.1 \%$ & $0.2 \%$ \\
$\begin{array}{c}\text { Mode shares } \\
2040\end{array}$ & $5.3 \%$ & $81.9 \%$ & $2.8 \%$ & $0.8 \%$ & $0.5 \%$ & $0.3 \%$ & $8.0 \%$ & $0.3 \%$ \\
\hline
\end{tabular}

Car

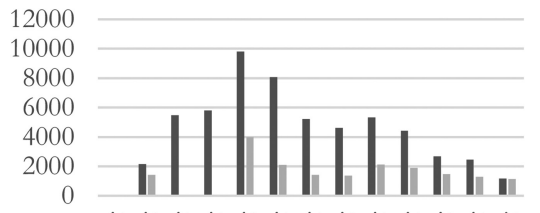

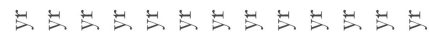

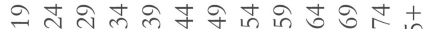

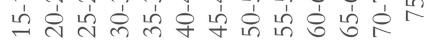

- Men 2020 Men 2040

\section{Cycling}

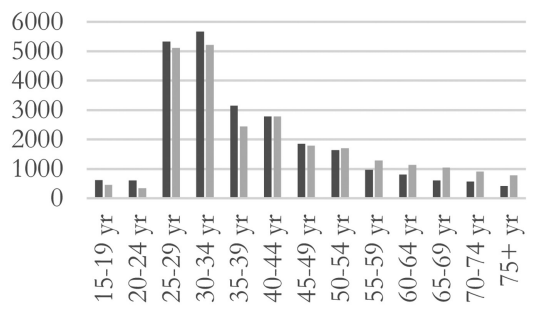

- Men 2020 - Men 2040

Walking

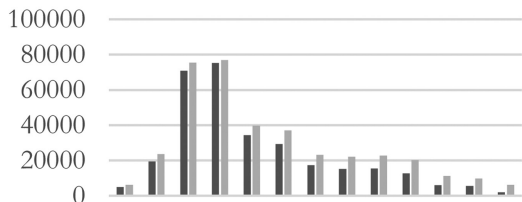

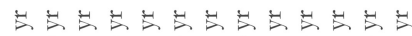

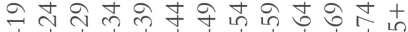

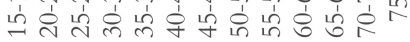

- Men 2020 - Men 2040
Car

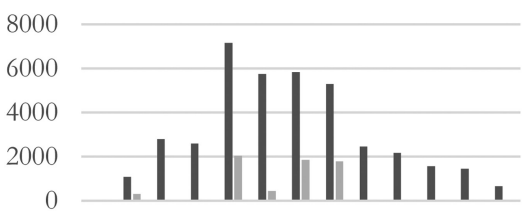

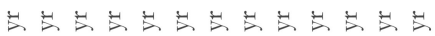

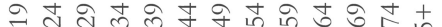

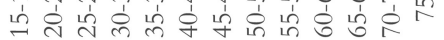

- Women 2020 - Women 2040

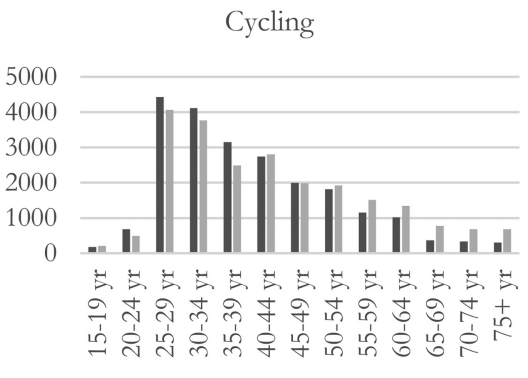

-Men 2020 - Men 2040

Walking

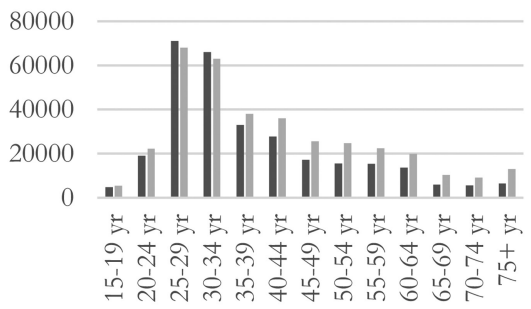

- Women 2020 - Women 2040

Figure 11.7 ZGO Scenario number of trips on select modes by age group and gender, short trips 
this demographic goes a long way in reaching the zero-growth objective at the aggregate level because they constitute a large part of overall daily mobility. The rising median age, however, counters some of the effects in ease of shifting 25-34-year-olds onto sustainable modes because, by 2040, this group will constitute a smaller share of Oslo's overall population and number of daily trips than today's scenario.

\section{Concluding discussion}

Our analyses reveal that Oslo has a vision, but it has not successfully linked mobility plans with climate action plans. Strategies for modifying travel behaviour saturate the plans targeting climate goals and are the central component of plans for lowering emissions. The path adopted for modifying travel behaviour for the city includes reducing car use through tolls, parking restrictions, land use specifications, locating businesses in the right place, nodal/hub development, densification, and a strategy for bicycling. This science-business frame is further bolstered by an active implementation of 'electrification of the transport sector' as part of the solutions to abate emissions and become fossil-free. Shared mobility, again a part of the science-business framing, is seen as part of a future which will operate with reduced car use.

On the surface, the plans and strategies for Oslo at all levels, and even those with a consolidated focus on climate strategies, do not prioritise building a knowledge base on different demographic groups and fails to acknowledge the persistent differences between the travel characteristics of men and women and across age groups. For instance, gendered travel patterns and their intersection with age is neither mentioned nor taken into cognizance in the different plans and strategies. It seems that gender balance is taken for granted, and there is a categorical lack of knowledge among planners on how to sharpen the focus of the proposed plans. The hypothesis that planners might think that it is not their jurisdiction to differentiate between demographic groups in the conceptualisation and drafting of plans is deeply problematic, and tends to lean towards the fissure identified in literature review of ignoring the ethical-justice frames, often associated with feminine characteristics. The plans will inevitably affect men and women differently and it is a lost opportunity if the already established clientele base for sustainable transport - i.e. women - are not given priority in the upcoming plans.

For example, the implementation of a bike-sharing scheme in Oslo was found to be lacking in being a viable option for women at its initial stages (Priya Uteng et al., 2020). Through trials and errors, a better understanding on how men and women are using the system differently is emerging and, consequently, women's use of Oslo's bike-sharing scheme has gone up in recent years (ibid). Similar findings have been recorded for car sharing around the world, putting women at a disadvantageous position compared to men in their uptake of these upcoming modes (Loose, 2010; Lenz, 2020). Clearly, the process of gender mainstreaming 
is lacking in the transport sector, which if applied can certainly strengthen the climate goals.

In short, the case of interlocking between climate goals and transport plans in Oslo has, to date, not been analysed from a gendered perspective. Building on Kronsell's (2013) words, the practice of regimes, and the norms that constitute the social order of the urban transport landscape, remain important for climate governance and, hence, need to be actively scrutinised for gendered outcomes. If the core principles of the plans addressing climate change and ZGO are taken in alliance with the discussions on gender and made more explicit, climate change mitigation and adaptation strategies can be better debated and addressed. Hiding these underlying trends is not only irresponsible but creates serious chasms between public policies and public acceptance of proposed plans.

Further, distribution impacts are not explicit in most of the planning documents. The need for a shift has been seen as necessary at all levels of government, but a disturbing aspect is that the combined plans for Oslo indicate that regional development would continue as before, regional car dependency would continue to increase and the targets for greenhouse gas reduction as well as the regional competitiveness would most likely not be reached (Plansamarbeidet, 2015).

From a methodological perspective, the usage of results from models like DEMOTRIPS should be routinised for municipalities and regional authorities based on regular feeds from different sources of big data, travel surveys and projections from Statistics Norway. In order to plot future travel behaviour scenarios for different regions and cities, disaggregated analyses of passenger transport in light of ageing, gendered travel patterns and preferences, societal megatrends (like digitalisation, etc.) and transport sector trends should inform both transport and climate plans and strategies.

To conclude, the existing knowledge gap on both the gendered profile of daily trips, portfolio of age-groups and their interaction with the different policy efforts aiming at modal shifts means that the current policies run a risk of being much less effective. Seeing that the entire zero-growth objective rests on the rationale that travellers can be simply steered towards alternative modes constitutes a real problem. For creating effective climate policies in the urban-transport planning sector, further empirical research is needed to design targeted measures and interventions addressing both gender and age, based on the principles of gender mainstreaming, in climate policy-making.

\section{Acknowledgement}

This study is a part of PLATON - a PLATform for Open and Nationally accessible climate policy knowledge - funded by The Norwegian Research Council (NRC) (grant number 295789). 


\section{Notes}

1 The zero-growth objective was introduced by the National Public Roads Administration in the National Transport Plan in 2014 for Norway's largest urban regions. The goal entails that the future growth in transport must be absorbed by public transport, cycling and walking and not by private car. In short, vehicle kilometres driven by private cars should either remain constant or go down in future.

2 The mode substitution factors are based on the likelihood of one mode replacing another depending on the prevalence of various trip purposes on the different modes. This was based on the Norwegian Travel Survey (NTS) 2013/14 which specifies the age, gender, trip purposes, trip length and mode used for each trip recorded in the NTS. The rationale for calculating mode substitution factors is that if, for example, cycling trips according to NTS constitute a high number of school trips and a low number of medical trips for a particular age group, one can assume that any new substituted cycling trip for that age group is more likely to be a school trip than a medical trip. These likelihoods are calculated across modes, age groups and trip purposes in the

$$
\text { following way: } L H(\text { purpose }=x \mid y)=\frac{\text { purpose }_{x}^{y}}{\sum_{i=1}^{n} \text { purpose }_{i}^{y}}
$$

The equation denotes the likelihood $(L H) \mathrm{f}$ a . trip on mode $y$. aving trip purpose $x$. or each age group. In short, it reflects the probability of a trip on transport mode $y$. aving travel purpose $x$.

\section{References}

Alston, M. (2014) 'Gender mainstreaming and climate change', Women's Studies International Forum, 47, pp. 287-294.

Bacchi, Carol, Eveline, Joan. (2010) Mainstreaming Politics: Gendering Practices and Feminist Theory. South Australia: University of Adelaide Press.

Beutel, A.M., Marini, M.M. (1995) 'Gender and values', American Sociological Review, 60(3), pp. 436-448.

C40 Cities Climate Leadership Group (2020) How to Build Back Better with a 15-Minute City [online]. Available at: https://www.c40knowledgehub.org/s/article/How-to-buildback-better-with-a-15-minute-city?language=en_US [Accessed: 20 November 2020].

de Jong, T., Fyhri, A., Priya Uteng, T. (2018) Gender gap-Perception of safety and cycling use, Workshop 2: Smart Mobilities-Walking and Biking, Nos-Sh workshop series, 21 April. Copenhagen, Denmark: University of Copenhagen.

Eagly, A.H. (1987) Sex Differences in Social Behavior: A Social-Role Interpretation. Hillsdale, NJ: Erlbaum.

Eagly, A.H., Wood, W., Diekman, A.B. (2000) Social Role Theory of Sex Differences and Similarities: A Current Appraisal. Mahwah, NJ: Lawrence Erlbaum Associates Publishers, pp. 123-174.

Economic, Social Council (ECOSOC) (1997) Gender Mainstreaming [online]. Available at: https://www.unwomen.org/en/how-we-work/un-system-coordination/gender-m ainstreaming [Accessed: 14 March 2020].

Gilligan, C. (1982) In A Different Voice: Psychological Theory and Women's Development. Harvard University Press, Cambridge, Massachusetts.

Heinen, E., Chatterjee, K. (2015) 'The same mode again? An exploration of mode choice variability in Great Britain using the national travel survey', Transportation Research, Part A: Policy and Practice, 78, pp. 266-282. 
Hjortol, Randi (2008) 'Daily mobility of men and women-a barometer of gender equality?, in T. Priya Uteng and T. Cresswell (eds.) Gendered Mobilities. Abingdon and New York: Routledge, pp. 193-210.

Hjorthol, R., Vågane, L. (2014) 'Allocation of tasks, arrangement of working hours and commuting in different Norwegian households', Journal of Transport Geography, 35, pp. $75-83$.

Hjorthol, R., Engebretesen, Ø., Priya Uteng, T. (2014) National Travel Survey-Key Results, 2013/14. TØI-report 1383/2014. Oslo: Norwegian Institute of Transport Economics.

Kim, C., Sang, S., Chun, Y., Lee, W. (2012) 'Exploring urban commuting imbalance by job and gender', Applied Geography, 32, pp. 532-545.

Kronsell, A. (2013) 'Gender and transition in climate governance', Environmental Innovation and Societal Transitions, 7, pp. 1-15.

Lenz, B. (2020) 'Smart mobility—-for all? Gender issues in the context of new mobility concepts', in T. Priya Uteng, H. Rømer Christensen, L. Levin (eds.) Gendering Smart Mobilities. Abingdon and New York: Routledge.

Loose, Willi (2010) Aktueller Stand des Car-Sharing in Europa. Endbericht D 2.4 Arbeitspaket 2; Bundesverband CarSharing [online]. Available at: http://www.carsharing.info/ima ges/stories/pdf_dateien/wp2_endbericht_deutsch_final_4.pdf [Accessed: 14 March 2020].

Magnusdottir, G., Kronsell, A. (2014) 'The (in)visibility of gender in Scandinavian climate policy-making', International Feminist Journal of Politics, 17(2), pp. 308-326.

Matthies, E., Kuhn, S., Klöckner, C.A. (2002) 'Travel mode choice of women. The result of limitation, ecological norm or weak habit?', Environment and Behavior, 34(2), pp. $163-177$.

Mavisakalyan, A., Tarverdi, Y. (2019) 'Do female parliamentarians make a difference?', European Journal of Political Economy, 56, pp. 151-164.

McCright, A.M. (2010) 'The effects of gender on climate change knowledge and concern in the American public', Population and Environment 32, pp. 66-87.

McCright, A.M., Dunlap, R.E. (2011) 'Cool dudes: The denial of climate change among conservative white males in the United States', Global Environmental Change, 21(4), pp. $1163-1172$.

Municipality of Haugesund (2014) Walking Strategy [online]. Available at: https://www .haugesund.kommune.no/om-kommunen/beredskap/beredskapsplan/lokaldemokrati/ kommuneplan/1352-gastrategi [Accessed: 14 March 2020].

Municipality of Oslo (2014) Oslo Bicycle Strategy 2015-2025 [online]. Available at: https ://www.oslo.kommune.no/gate-transport-og-parkering/sykkel/sykkelstrategier-og-do kumenter/\#gref [Accessed: 14 March 2020].

Municipality of Oslo (2015) Municipal Master Plan 2015 Towards 2030 [online]. Available at: https://www.oslo.kommune.no/politikk/kommuneplan/ [Accessed: 14 March 2020].

Municipality of Oslo (2016) Climate and Energy Strategy for Oslo. Municipality of Oslo [online]. Available at: https://www.oslo.kommune.no/miljo-og-klima/slik-jobber-vi -med-miljo-og-klima-1/miljo-og-klimapolitikk/klima-og-energistrategi/ [Accessed: 14 March 2020].

Municipality of Oslo (2019) Municipal Master Plan for Oslo, Societal Element, 2018 Towards 2040 [online]. Available at: https://www.oslo.kommune.no/politikk/kommuneplan/ [Accessed: 14 March 2020].

Plansamarbeidet (2015) Regional Plan for Land Use and Transport in Oslo and Akershus. County of Viken [online]. Available at: https://viken.no/tjenester/planlegging/samfun nsplanlegging/regionale-planer/ [Accessed: 14 March 2020]. 
Polk, M. (2003) 'Are women potentially more accommodating than men to a sustainable transportation system in Sweden?', Transportation Research Part D, 8, pp. 75-95.

Priya Uteng, T., Cresswell, T. (eds.) (2008) Gendered Mobilities. Ashgate: Aldershot.

Priya Uteng, T., Espegren, H.M., Throndsen, T.S., Bocker, L. (2020) 'The gendered dimension of multi-modality: Exploring the bike sharing scheme of Oslo', in T. Priya Uteng, H. Rømer Christensen, L. Levin (eds.) Gendering Smart Mobilities. Abingdon and New York: Routledge.

Ruter. (2016) M2016. Public transport and mobility strategy, Ruter [online]. Available at: https://ruter.no/om-ruter/strategier-og-handlingsplaner/M2016/ [Accessed: 14 March 2020].

Saeterøy Maridal, J. (2018) Projecting Sustainable Mobility Scenarios for Oslo towards 2040: The Potential of Car-Sharing, Ridesharing and Cycling. Master's thesis in Entrepreneurship, Innovation and Society. Trondheim: NTNU.

Sandow, E. (2008) 'Commuting behaviour in sparsely populated areas: Evidence from northern Sweden', Journal of Transport Geography, 16(1), pp. 14-27.

Sandow, E., Westin, K. (2010) 'The persevering commuter-Duration of long-distance commuting', Transportation Research Part A, 44, pp. 433-445.

Scheiner, J. (2018) Gender, travel and the life course. Thoughts about recent research, Workshop 3: Smart Mobilities, Planning and policy processes-Gender and diversity mainstreaming 17-18 September. Stockholm, Sweden: VTI.

Scheiner, J., Sicks, K., Holz-Rau, C. (2011) 'Gendered activity spaces: Trends over three decades in Germany', Erdkunde, 65(4), pp. 371-387.

Sovacool, B.K., Noel, L., Kester, J., de Rubens, G.Z. (2018) 'Reviewing Nordic transport challenges and climate policy priorities: Expert perceptions of decarbonisation in Denmark, Finland, Iceland, Norway, Sweden', Energy, 165, pp. 532-542.

Svanfelt, D. (2018) Gender equality and equity in urban planning, Workshop 3: Smart Mobilities, Planning and Policy Processes-Gender and Diversity Mainstreaming 17-18 September. Stockholm, Sweden: VTI.

Swim, J.K., Vescio, T.K., Dahl, J.L., Zawadzki, S.J. (2018) 'Gendered discourse about climate change policies', Global Environmental Change, 48, pp. 216-225.

Winslott Hiselius, L., Smidfelt, L., Kronsell, A., Dymén, C. (2019) 'Investigating the link between transport sustainability and the representation of women in Swedish local committees', Sustainability, 11(17), 4728. https://doi.org/10.3390/su11174728

Wittman, Amanda. (2010) 'Looking local, finding global: Paradoxes of gender mainstreaming in the Scottish executive', Review of International Studies, 36, pp. 51-76. 